\title{
The Thermochemistry of Gold
}

\section{FUNDAMENTAL DATA FOR THE SOLUTION OF PRACTICAL PROBLEMS}

\author{
O. Kubaschewski and 0 . von Goldbeck
}

Lehrstuhl für Theoretische Hüttenkunde, Technische Hochschule, Aachen, West Germany

Thermodynamic principles and data are important to the understanding of the properties of materials and to the development of improved products, as they can help to describe alloying characteristics, high temperature behaviour and the properties of compounds. In this paper the authors present collected thermodynamic values for gold and go on to show how they can be used to determine equilibrium phase relationships in gold alloys.

\author{
The Physico-chemical Properties of Gold \\ Structure: face-centred cubic \\ Atomic radius: $1.435 \AA$ \\ Melting point: $1064.43^{\circ} \mathrm{C}$ \\ Normal boiling point: $2860^{\circ} \mathrm{C}$ \\ Standard entropy (solid): $11.35 \pm 0.05 \mathrm{cal} / \mathrm{K}$.g-atom \\ Standard entropy (ideal gas): $43.115 \mathrm{cal} / \mathrm{K}$.g-atom \\ Heat of fusion $\left(1064^{\circ} \mathrm{C}\right): 3.0 \pm 0.1 \mathrm{kcal} / \mathrm{g}$-atom \\ Heat of sublimation $\left(25^{\circ} \mathrm{C}\right): 88.0 \pm 0.3 \mathrm{kcal} / \mathrm{g}$-atom \\ Heat of evaporation $\left(2860^{\circ} \mathrm{C}\right): 79.9 \pm 0.5$ \\ $\mathrm{kcal} / \mathrm{g}$-atom \\ Heat capacity (solid): $6.064-0.173 \times 10^{-3} \mathrm{~T}$ \\ $+1.01 \times 10^{-6} \mathrm{~T}^{2}$ \\ Heat capacity (liquid): 7.40 (increasing with \\ decreasing temperature near the melting point) \\ Heat capacity (gas): 4.97 (increasing with \\ temperature above $1000^{\circ} \mathrm{C}$ ) \\ (Heat capacities are given in cal/K.g-atom) \\ Ionisation potential : $9.23 \mathrm{eV}$ \\ Electronegativity: 2.25
}

The thermochemical properties of the compounds and intermetallic phases of gold have been fairly well investigated. This is possibly due less to their technological interest than because the metal is relatively simple to handle experimentally; it does not easily react with non-metals, has a good oxidation resistance and a "convenient" melting point, and is ductile. It is the only metal that is stable at room temperature in air.

The Gibbs energy of formation of gold oxide, $\mathrm{Au}_{2} \mathrm{O}_{3}$, may be represented (1) by the equation:

$\Delta \mathrm{G}_{\mathrm{f}}^{\mathrm{o}}=-2160+95.14 \mathrm{~T}-10.36 \mathrm{~T} \log \mathrm{T}(\mathrm{kcal} / \mathrm{mole})$ from which it follows hypothetically that $\mathrm{Au}_{2} \mathrm{O}_{3}$ is only stable below $28 \mathrm{~K}$, though no significance must be attached to this number.

The reason for this behaviour is the high ionisation energy which implies a "reluctance" of gold to form ionic compounds. It may be seen from Table I that the heats of formation of the predominantly polar (ionic) compounds, such as the halides, are relatively small so that the Gibbs energies of formation obtained from the Gibbs-Helmholtz equation

$$
\Delta \mathrm{G}_{\mathrm{f}}=\Delta \mathrm{H}_{\mathrm{f}}-\Delta \mathrm{S}_{\mathrm{f}} \mathrm{T}
$$

become positive (implying metastability) at relatively

\begin{tabular}{|c|c|c|c|c|}
\hline $\begin{array}{l}\text { Heats } \\
\text { Stand }\end{array}$ & $\begin{array}{cc} & T \\
\text { of } & \text { Formation } \\
\text { d } & \text { Entropies } \\
\text { Gold }\end{array}$ & $\begin{array}{l}\text { able I } \\
(\Delta \mathbf{H}) \text { i } \\
\left(\mathbf{S}_{293}\right) \\
\text { compour }\end{array}$ & $\begin{array}{ll}\text { n } & \mathrm{kcal} / \mathrm{mole} \\
\mathrm{n} & \mathrm{cal} / \mathrm{K} . \mathrm{mo} \\
\text { dds }\end{array}$ & and \\
\hline $\begin{array}{l}\text { Com- } \\
\text { pound }\end{array}$ & $\Delta \mathrm{H}$ & $\underset{{ }^{\circ} \mathrm{C}}{\text { Temp. }}$ & $\mathrm{S}_{298}$ & $\begin{array}{c}\text { Refer- } \\
\text { ence }\end{array}$ \\
\hline $\mathrm{AuF}_{3}$ & $-86.9 \pm 2.2$ & 25 & & - \\
\hline $\mathrm{AuCl}$ & $-8.3 \pm 1.0$ & 25 & $22.2 \pm 1.5$ & (15) \\
\hline $\mathrm{AuCl}_{3}$ & $-27.5 \pm 1.0$ & 25 & $35.4 \pm 1.6$ & (15) \\
\hline $\mathrm{AuBr}$ & $-3.3 \pm 1.0$ & 25 & 27.0 & (15) \\
\hline AuI & $+0.2 \pm 1.0$ & 25 & 28.5 & (15) \\
\hline $\mathrm{Au}_{2} \mathrm{O}_{3}$ & -0.82 & 25 & 31.15 & (1) \\
\hline $\mathrm{AuSe}$ & -3.3 & 25 & 18.1 & (7) \\
\hline $\mathrm{AuTe}_{2}$ & $-4.45 \pm 0.7$ & 25 & $33.85 \pm 0.1$ & (7) \\
\hline $\mathrm{Au}_{2} \mathrm{P}_{3}$ & $-23.3 \pm 3.5$ & 25 & $36.0 \pm 3.0$ & (15) \\
\hline $\mathrm{AuSb}_{2}$ & $-3.12 \pm 0.2$ & 0 & & (5) \\
\hline $\mathrm{AuSn}$ & $-7.28 \pm 0.3$ & 25 & $23.45 \pm 0.8$ & (5) \\
\hline $\mathrm{AuPb}_{2}$ & $-1.5 \pm 0.4$ & 25 & $41.9 \pm 0.3$ & (15) \\
\hline $\mathrm{AuAl}_{2}$ & $-27.1 \pm 2.5$ & 20 & $\sim 25.8$ & (16) \\
\hline $\mathrm{AuAl}$ & $-15.6 \pm 2.2$ & 20 & $\sim 18.0$ & (16) \\
\hline $\mathrm{Au}_{2} \mathrm{Al}$ & $-20.0 \pm 3.0$ & 20 & $\sim 25.2$ & (16) \\
\hline AuGa & $-11.45 \pm 0.4$ & 433 & & (17) \\
\hline $\mathrm{AuGa}_{2}$ & $-17.82 \pm 0.4$ & 427 & & (17) \\
\hline
\end{tabular}




\begin{tabular}{|c|c|c|c|c|c|c|c|}
\hline \multicolumn{8}{|c|}{$\begin{array}{l}\text { Table II } \\
\text { Heats of Solution of Various (Solid) Metals (Me) in Solid Gold } \\
\text { (Numbers Indicate Values of } \Delta \overline{\mathbf{H}}_{M e} \text { in cal/g-atom Me) }\end{array}$} \\
\hline \multirow{2}{*}{ Me } & \multirow{2}{*}{ Temp. ${ }^{\circ} \mathrm{C}$} & \multicolumn{5}{|c|}{$\mathrm{N}_{\mathrm{Me}}$} & \multirow{2}{*}{ Reference } \\
\hline & & 0.0 & 0.1 & 0.2 & 0.3 & 0.5 & \\
\hline $\mathrm{Fe}$ & 850 & 6090 & 4415 & 3378 & 2870 & 2310 & (5) \\
\hline Co & 877 & 9590 & 8880 & & & & (5) \\
\hline $\mathrm{Ni}$ & 877 & 5140 & 4845 & 4380 & 3770 & 2235 & (18) \\
\hline $\mathrm{Pd}$ & - & -11140 & -7710 & -5060 & -3085 & -765 & (14) \\
\hline $\mathrm{Pt}$ & - & -635 & +510 & +1215 & +1550 & +1430 & (14) \\
\hline $\mathrm{Cu}$ & 527 & -2780 & -2960 & -2870 & -2610 & -1765 & (5) \\
\hline $\mathrm{Ag}$ & 527 & -4040 & -3400 & -2790 & -2220 & -1215 & (5) \\
\hline $\mathrm{Cd}$ & 427 & -15600 & -13200 & -11800 & -9390 & & (5) \\
\hline $\mathrm{Hg}$ & 227 & -1270 & -530 & & & & (5) \\
\hline
\end{tabular}

\begin{tabular}{|c|c|c|c|c|c|c|c|}
\hline \multicolumn{8}{|c|}{$\begin{array}{c}\text { Table III } \\
\text { Excess Entropies of Solution of Various (Solid) Metals (Me) in Solid Gold } \\
\text { (Numbers indicate values of } \Delta \overline{\mathbf{S}}_{\mathrm{Me}}^{\mathrm{se}} \text { in cal/K.g-atom Me) }\end{array}$} \\
\hline \multirow{2}{*}{$\mathrm{Me}$} & \multirow{2}{*}{ Temp. ${ }^{\circ} \mathrm{C}$} & \multicolumn{5}{|c|}{$\mathrm{N}_{\mathrm{Me}}$} & \multirow{2}{*}{ Reference } \\
\hline & & 0.0 & 0.1 & 0.2 & 0.3 & 0.5 & \\
\hline $\mathrm{Fe}$ & 850 & 5.20 & 3.03 & 1.715 & 1.11 & 0.77 & (5) \\
\hline Co & 877 & 2.0 & 3.52 & & & & (5) \\
\hline $\mathrm{Ni}$ & 877 & 1.21 & 1.515 & 1.60 & 1.51 & 0.85 & (18) \\
\hline $\mathrm{Pd}$ & - & -3.0 & -2.43 & -1.92 & -1.47 & -0.75 & (14) \\
\hline $\mathrm{Pt}$ & - & -3.5 & -2.41 & -1.58 & -0.95 & -0.225 & (14) \\
\hline $\mathrm{Cu}$ & 527 & +0.61 & +0.36 & +0.21 & +0.094 & -0.034 & (5) \\
\hline $\mathrm{Ag}$ & 527 & -1.39 & -1.12 & -0.88 & -0.67 & -0.34 & (5) \\
\hline $\mathrm{Cd}$ & 427 & -8.36 & -5.18 & -5.01 & -3.81 & & (5) \\
\hline $\mathrm{Hg}$ & 227 & -2.0 & -1.14 & & & & (5) \\
\hline
\end{tabular}

low temperatures. For $\mathrm{AuCl}, \Delta \mathrm{G}_{\mathfrak{f}}^{\mathrm{o}}=$ zero at about $250^{\circ} \mathrm{C}$, and for $\mathrm{AuF}_{3}$ at a temperature somewhat above the melting point of the metal. Thus, gold fluoride is the most stable polar compound of the metal, as might be expected.

Gold sulphides are metastable and gold is therefore suitable for the determination of sulphur potentials in the gas phase by electromotive force methods involving solid electrolytes (2).

Other compounds listed in Table I exhibit significant heats of formation, in particular the phosphide and the aluminides. In these cases one may assume the formation of strong covalent bonds, although the mechanism is not yet clear (see, for instance, ref. (3) on aluminides).

Turning now to the systems of gold with metals proper, one finds that gold alloys readily with other metals-it is alloyphilic. To some extent the causes for this phenomenon are known. With the meta-metals zinc and cadmium, for example, gold forms the socalled Hume-Rothery phases which are stabilised by certain electron ratios, subject to much speculation by the solid state physicists (see, for example, ref. (4)).

Other factors to be considered with respect to phase stability are the atomic sizes and the heats of sublimation of the component metals relative to those for gold. It has been demonstrated by Kubaschewski that the ratio of the atomic radii, $r_{A} / r_{B}$, of two metals $A$ and $B$ ( $A$ being the larger) in conjunction with the ratio of the heats of sublimation, $\mathrm{L}_{A} / \mathrm{L}_{B}$, may be used to predict the stability of certain crystallographic structures. If the ratio $L_{A} / L_{B}$ is larger than unity $\left(r_{A} / r_{B}\right.$ being so by definition), the number of the stronger metallic bonds is increased by tighter atomic packing and stable intermetallic phases may thus form. If $L_{A} / L_{B}$ is smaller than unity, only the number of weaker bonds increases and the tendency to form intermetallic phases ceases. 
Gold has a fairly high atomic radius, as well as a high heat of sublimation, and these partly account for its alloyphilic nature. According to this model, the compound $\mathrm{AuBe}$ would not be expected to form, but here the large difference in electronegativity contributes a polar bond which acts as a stabiliser. With metals having similar heats of sublimation gold forms wide ranges of solid solutions, provided that the difference in atomic size does not exceed about 15 per cent. The partial heats of solution of a number of metals, $\mathrm{Me}$, in gold $\left(\triangle \overline{\mathrm{H}}_{\mathrm{Me}}\right)$ are tabulated in Table II and the corresponding partial excess entropies $\left(\Delta \bar{S}_{M e}^{\mathrm{xs}}\right)$ in Table III. Excess entropies are obtained from the measured entropies $\left(\Delta \bar{S}_{M e}^{\mathrm{xpl}}\right)$ by adding the negative disorder term:

$$
\Delta \overline{\mathrm{S}}_{\mathrm{Me}}^{\mathrm{xs}}=\Delta \overline{\mathrm{S}}_{\mathrm{Me}}^{\mathrm{xptl}}+4.574 \log \mathrm{N}_{\mathrm{Me}}
$$

where $\mathrm{N}_{M e}$ is the atomic fraction (atomic percent) 100) of $\mathrm{Me}$ in the solution.

Integral heats and excess entropies of mixing $\left(\Delta \mathrm{H}, \Delta \mathrm{S}^{\mathrm{xs}}\right)$ are listed in Tables IV and $\mathrm{V}$. The connection between the integral and partial values is given $\left(\mathrm{Z}=\mathrm{H}\right.$ or $\left.\mathrm{S}^{\mathrm{xs}}\right)$ by:

$$
\Delta \mathrm{Z}=\mathrm{N}_{\mathrm{Au}} \Delta \overline{\mathrm{Z}}_{\mathrm{Au}}+\mathrm{N}_{\mathrm{Me}} \Delta \overline{\mathrm{Z}}_{\mathrm{Me}}
$$

The reason for tabulating partial as well as integral heats and entropies is that in application sometimes the one, sometimes the other quantity, is more convenient.

Metals of different atomic size are more easily adapted in liquid solution so that the homogeneity ranges are wider than in the solid state. Tables IV and $\mathrm{V}$ give integral thermochemical values for some liquid solutions. In addition, incomplete sets of data are available for the following systems: $\mathrm{Au}-\mathrm{Mn}$, $\mathrm{Au}-\mathrm{In}, \mathrm{Au}-\mathrm{Si}(5)$, and $\mathrm{Au}-\mathrm{U}$ (6). Mills (7) lists data for the gaseous species AuS.

In practical applications gold alloys rather than pure gold are usually employed because of the mechanical softness of the metal. By alloying, however, one loses its greatest merit, freedom from oxidation. When on one occasion the question was posed to the authors whether platinum might be replaced in electrical contacts by gold, measurements were made on the oxidation behaviour of platinum and gold alloyed with 5 and 10 per cent copper and of nickel respectively (8). In general, the gold alloys were found to oxidise more rapidly, but owing to the affinity of copper and nickel for the solvents the dissociation pressure of the oxides is significantly increased, so that the partial pressure of oxygen in air is reached at a lower temperature above which the alloy must remain unattacked. This temperature can be calculated, if the Gibbs energies $\Delta G_{1}^{\circ}$ and $\Delta G_{2}^{\circ}$ in the following scheme are known.

$$
\begin{array}{rlrl}
4 \mathrm{Cu}+\mathrm{O}_{2} & =2 \mathrm{Cu}_{2} \mathrm{O} & \Delta \mathrm{G}_{1}^{\circ} & \text { minus } \\
4 \mathrm{Cu} & =4[\mathrm{Cu}]_{\mathrm{Au}_{\mathrm{x}} \mathrm{Cu}_{y}} & \Delta \overline{\mathrm{G}}_{2}^{\circ} & \text { plus } \\
2 \mathrm{Cu}_{2} \mathrm{O} & =4[\mathrm{Cu}]_{\mathrm{Au}_{\mathrm{x}} \mathrm{Cu}_{\mathrm{y}}}+\mathrm{O}_{2} & \Delta \overline{\mathrm{G}}_{2}^{\circ}-\Delta \mathrm{G}_{1}^{\circ}
\end{array}
$$

\begin{tabular}{|c|c|c|c|c|c|c|c|c|}
\hline \multicolumn{9}{|c|}{$\begin{array}{c}\text { Table IV } \\
\text { Integral Heats of Mixing of Solid and Liquid Solutions of Gold Alloys in keal/g-atom }\end{array}$} \\
\hline \multirow{2}{*}{$\mathrm{Me}$} & \multirow{2}{*}{ Temp. ${ }^{\circ} \mathrm{C}$} & \multirow{2}{*}{ Aggrgn. } & \multicolumn{5}{|c|}{$\mathrm{N}_{\mathrm{Me}}$} & \multirow{2}{*}{ Reference } \\
\hline & & & 0.2 & 0.4 & 0.5 & 0.6 & 0.8 & \\
\hline $\mathrm{Fe}$ & 850 & solid & 900 & 1330 & \multirow[t]{2}{*}{1480} & \multirow{2}{*}{1550} & \multirow[b]{3}{*}{1205} & (5) \\
\hline $\mathrm{Fe}$ & 1110 & liquid & 680 & 970 & & & & (19) \\
\hline $\mathrm{Ni}$ & 877 & solid & 958 & 1640 & 1810 & 1805 & & (18) \\
\hline $\mathrm{Pd}$ & - & solid & -1520 & -1895 & -1780 & -1505 & -750 & (14) \\
\hline $\mathrm{Pt}$ & - & solid & +100 & +455 & +635 & +760 & +707 & (14) \\
\hline $\mathrm{Cu}$ & 527 & solid & -580 & -1075 & -1220 & -1280 & -895 & (5) \\
\hline $\mathrm{Cu}$ & 1277 & liquid & -625 & -980 & -1045 & -1025 & -710 & (5) \\
\hline $\mathrm{Ag}$ & 527 & solid & 670 & -1045 & -1110 & -1085 & --750 & (5) \\
\hline $\mathrm{Ag}$ & 1077 & liquid & -785 & -1180 & -1230 & -1180 & -785 & (5) \\
\hline $\mathrm{Zn}$ & 807 & liquid & -2990 & -5060 & -5435 & -5255 & -3265 & (5) \\
\hline $\mathrm{A} 1$ & 1065 & liquid & -6880 & -9820 & -9875 & -9065 & -5605 & (16) \\
\hline $\mathrm{Tl}$ & 700 & liquid & & $\begin{array}{l}+\quad 27 \\
\end{array}$ & $+\quad 34$ & +33 & +16 & (5) \\
\hline $\mathrm{Ge}$ & 1150 & liquid & -890 & -1150 & -1120 & -1020 & -585 & (11) \\
\hline $\mathrm{Sn}$ & 550 & liquid & -1890 & -2750 & -2765 & -2540 & -1470 & (5) \\
\hline $\mathrm{Pb}$ & 927 & liquid & -160 & -190 & -165 & -135 & + & (5) \\
\hline $\mathrm{Bi}$ & 700 & liquid & & 135 & 150 & 143 & 90 & (5) \\
\hline
\end{tabular}

where the square brackets indicate solution of copper in the alloy of given composition $x, y$. The dissocia- 
Table V

Integral Excess Entropies of Mixing of Solid and Liquid Solutions of Gold Alloys in cal/K.g-atom

\begin{tabular}{|c|c|c|c|c|c|c|c|c|}
\hline \multirow{2}{*}{$\mathrm{Me}$} & \multirow{2}{*}{ Temp. ${ }^{\circ} \mathrm{C}$} & \multirow{2}{*}{ Aggrgn. } & \multicolumn{5}{|c|}{$\mathrm{N}_{\mathrm{Me}}$} & \multirow{2}{*}{ Reference } \\
\hline & & & 0.2 & 0.4 & 0.5 & 0.6 & 0.8 & \\
\hline $\mathrm{Fe}$ & 850 & solid & 0.615 & 0.75 & \multirow[t]{2}{*}{0.76} & & & (5) \\
\hline $\mathrm{Fe}$ & 1110 & liquid & 0.56 & 0.60 & & & & (19) \\
\hline $\mathrm{Ni}$ & 877 & solid & 0.30 & 0.59 & 0.67 & 0.66 & 0.375 & (5) \\
\hline $\mathrm{Pd}$ & - & solid & -0.48 & -0.72 & -0.75 & -0.72 & -0.48 & (14) \\
\hline $\mathrm{Pt}$ & - & liquid & -0.48 & -0.59 & -0.55 & -0.46 & -0.24 & (14) \\
\hline $\mathrm{Cu}$ & 527 & solid & +0.073 & +0.08 & +0.07 & +0.045 & +0.037 & (5) \\
\hline $\mathrm{Cu}$ & 1277 & liquid & +0.19 & +0.26 & +0.255 & +0.23 & +0.135 & (5) \\
\hline $\mathrm{Ag}$ & 527 & solid & -0.22 & -0.33 & -0.345 & -0.33 & -0.22 & (5) \\
\hline $\mathrm{Ag}$ & 1077 & liquid & -0.327 & -0.465 & -0.47 & -0.435 & -0.27 & (5) \\
\hline $\mathrm{Zn}$ & 807 & liquid & +0.065 & -0.335 & -0.493 & -0.565 & -0.36 & (5) \\
\hline $\mathrm{Al}$ & 1065 & liquid & +0.10 & -0.01 & -0.03 & +0.01 & +0.30 & (16) \\
\hline $\mathrm{T} 1$ & 700 & liquid & & +0.45 & +0.50 & +0.50 & +0.345 & (5) \\
\hline $\mathrm{Ge}$ & 1150 & liquid & -0.14 & -0.06 & +0.03 & +0.08 & +0.17 & (11) \\
\hline $\mathrm{Sn}$ & 550 & liquid & 0.564 & 0.41 & 0.315 & 0.23 & 0.15 & (5) \\
\hline $\mathrm{Pb}$ & 927 & liquid & 0.27 & 0.41 & 0.425 & 0.415 & 0.365 & (5) \\
\hline $\mathrm{Bi}$ & 700 & liquid & & 0.285 & 0.30 & 0.285 & 0.185 & (5) \\
\hline
\end{tabular}

Notes

In Tables II to V, $\mathrm{N}_{M e}$ represents atomic fraction (at. \%/100) of the second metal.

In Tables IV and $V$, the standard states of the component metals are always taken to be the same as that of the alloy in column 3 .

tion pressure of cuprous oxide in equilibrium with the alloy $\left(\mathrm{p}_{\mathrm{O}_{2}}\right)$ is obtained from the equation:

$$
\Delta \overline{\mathrm{G}}_{\mathrm{O}_{2}}^{\circ}-\Delta \mathrm{G}_{1}^{\circ}=-4.574 \mathrm{~T} \log \mathrm{p}_{\mathrm{O}_{z}} .
$$

In this way, the dissociation pressure in air of the 5 per cent copper-gold alloy was calculated to be $1020^{\circ} \mathrm{C}$, which is, however, close to the melting point of gold.

Its relatively low melting point limits, indeed, the usefulness of gold in high-temperature technology with which the present authors are mainly concerned. An example of this disadvantage is the use of gold as container material instead of platinum for the production of super-pure glass, with which the latter metal shows certain shortcomings (9).

\section{Calculation of Equilibrium Diagrams}

Probably the most important practical application of thermochemical data in the case of gold is the calculation of binary and multi-component equilibrium diagrams, the principle of which has recently been outlined by Kubaschewski and Barin (10). It consists, to put it briefly, in calculating the Gibbs energy $v s$ concentration curves (in a binary system) or surfaces (in a ternary one) and to find the tangents which touch the $\Delta \mathrm{G}^{\circ}$ curves or surfaces at the phase boundaries, heterogeneous-homogeneous. As an example, for the simplest case the liquidus curve in a eutectic system, gold-thallium, is shown in Figure 1. The agreement with the experimental curve is good

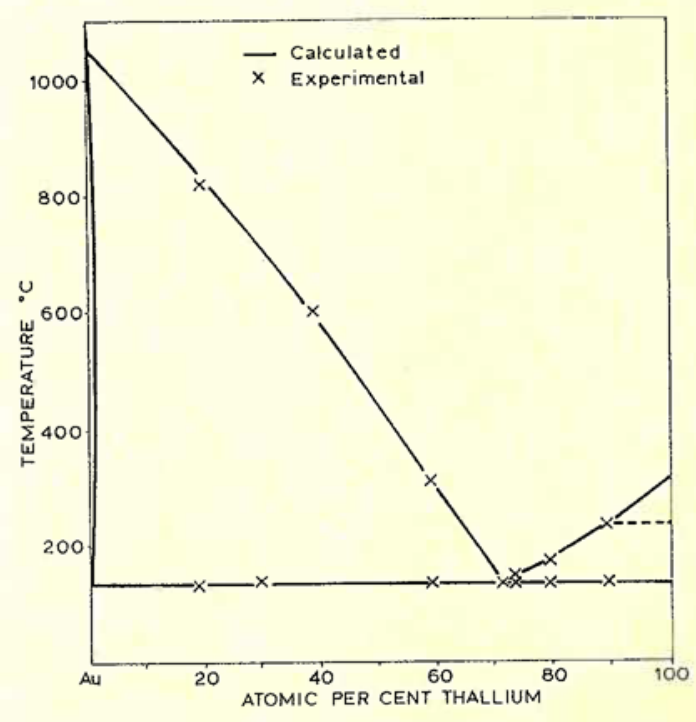

Fig. 1 Experimental and calculated equilibrium diagram of the system gold-thallium, showing the excellent agreement. In this case the calculation has taken account of a finite difference (5) in the heat capacities of alloyed and unalloyed thallium 


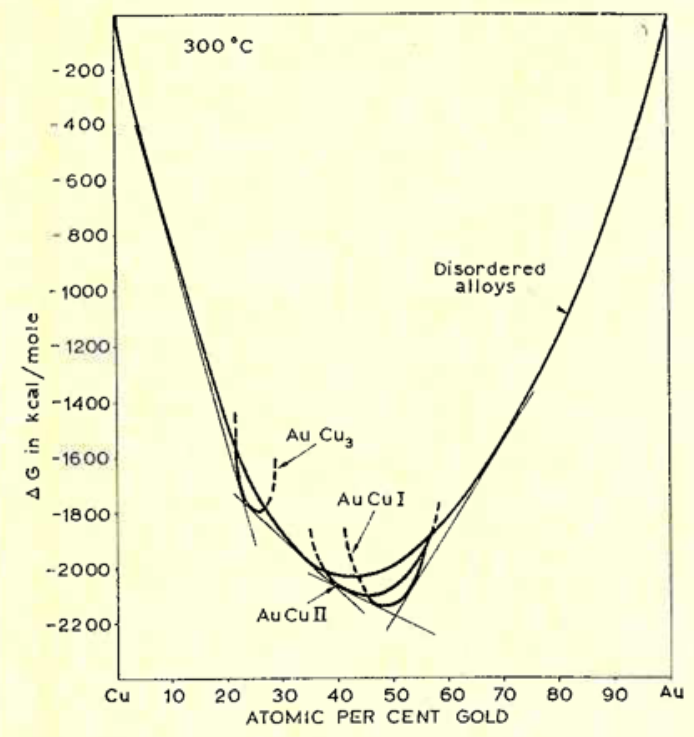

Fig. 2 Gibbs energies of formation of the ordered and disordered phases in the system gold-copper at $300^{\circ} \mathrm{C}$

and there is no problem. One may reverse the procedure and calculate the entropies of solution from the corresponding heats and the established liquidus curve. This has been applied to the gold-germanium system by Predel and Stein (11).

The gold-silver system provides the classical example for a demonstration of the superiority of the thermochemical method over the conventional methods for phase boundary determination because the former is less affected by kinetic checks than the latter. C. Wagner (12) calculated the width of the solidus-liquidus gap at 50 atomic per cent and found it to be $1.3^{\circ} \mathrm{C}$ rather than $\sim 10^{\circ} \mathrm{C}$ obtained experimentally. Meanwhile, very thorough investigations have shown the calculated value to be correct.

The equilibria of the various superstructures with the disordered solid solutions in the system goldcopper are more involved. Figure 2 shows the

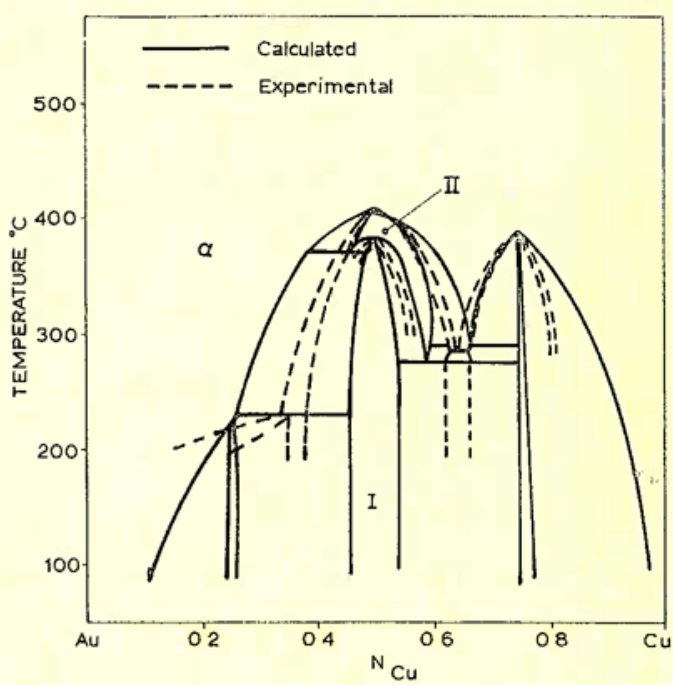

Fig. 3 Experimental and calculated phase boundaries of the ordered phases in the system gold-copper in equilibrium with the disordered solid solutions

Gibbs energy $v s$. concentration curves at one representative temperature, $300^{\circ} \mathrm{C}$. The tangents are also shown, indicating the principle of the determination of the phase boundaries outlined above. By repeating the graphical evaluation of the phase boundaries at a series of temperatures, they can be constructed and are shown as full lines in Figure 3. The agreement with the experimental boundaries is not too good. Both the conventional and thermochemical measurements suffer from kinetic delays in equilibration, and it must be concluded that further studies with prolonged annealing times are necessary to establish the phase boundaries accurately.

Potentially still more useful is the calculation of phase boundaries in ternary systems on the basis of the thermochemical data of the pertinent binaries. In this case it is no longer possible to apply the graphical method of evaluation. Heats and entropies

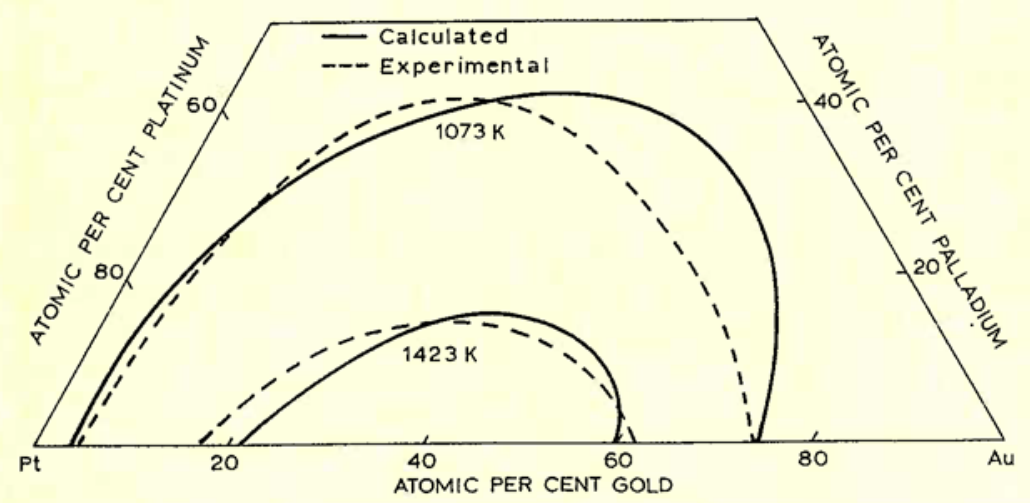

Fig. 4 Experimental and calculated phase boundary of the miscibility gap in the system gold-palladium-platinum at two temperatures 
are therefore expressed in the form of polynomials and the tangent planes to the resulting Gibbs energy surfaces are evaluated by computer. Modes of extrapolating the binary data into ternary ranges are being explored at present empirically. Among other examples, Spencer and Hayes (13) have estimated the excess Gibbs energies of liquid gold-silver-copper solutions by two such methods and shown them to agree rather well with the experimental results.

An example of a calculated phase boundary in a ternary system may be seen from Figure 4, in which the boundary of the miscibility gap in the system gold-palladium-platinum is compared with the experimental boundary at two temperatures (14). The agreement is admittedly modest, but shows the order of agreement that can be obtained at present. However, the development of the method is being quite energetically pursued by an international working group called CALPHAD ("Calculation of Phase Diagrams"), which is not unexpectedly working on alloyed steels and similar alloys of wide technological importance but can handle any ternary or even higher system for which sufficient basic thermochemical data are accurately known.

Thus, with some encouragement from those interested in the noble metals and their alloys, the application of chemical thermodynamics to the development of these materials could be considerably extended.

\section{References}

1 G. Ondracek and H. Wedemeyer, "Freie Bildungsenthalpien \& Metall-Keramik Wechselwirkungen", Inst. f Material- u. Festkörperforschung, Kernforschungszentrum Karlsruhe (1974)

2 T. Rosenqvist, Private Communication, February 1975

3 O. Kubaschewski and G. Heymer, Trans. Farad. Soc., 1960, 56, 473

4 P. S. Rudman, J. Stringer and R. I. Jaffee (Ed.), "Phase Stability in Metals and Alloys", Battelle Mem. Inst. Coll., Geneva \& Villars, 1967

5 R. Hultgren et al., "Selected Values of Thermodynamic Properties of Metals and Alloys", Wiley, 1974

6 C. B. Alcock and P. Grieveson, 7. Inst. Metals, 1962, 90, 304

7 K. C. Mills, "Thermodynamic Data for Inorganic Sulphides, Selenides \& Tellurides", Butterworths, 1974

8 O. Kubaschewski, Z. Elektrochem., 1943, 49, 446

9 O. Kubaschewski, Platinum Metals Rev., 1971, 15, 134

10 O. Kubaschewski and I. Barin, Pure \& Appl. Chem., 1974, 38, 469

11 B. Predel and D. W. Stein, Z. Naturforsch., 1971, 26a, 722

12 C. Wagner, Acta Metall, 1954, 2, 242

13 P. J. Spencer, F. H. Hayes and O. Kubaschewski, Rev. Chim. Minér., 1972, 9, 13

14 O. Kubaschewski and J. F. Counsell, Monatsh. Chemie, $1971,102,1724$

15 O. Kubaschewski and C. B. Alcock, "Metallurgical Thermochemistry", 4th Ed., Pergamon, 1967

16 B. Predel and H. Ruge, Z. Metallkunde, 1972, 63, 59

17 B. Predel and D. W. Stein, Acta Metall., 1972, 20, 681

18 B. Predel and E. Zehnpfund, Thermochimica Acta, 1974, 8,283

19 B. Predel and E. Zehnpfund, Z. Metallkunde, 1973, 64, 782

\section{Improvements in Gold Extraction Metallurgy}

For many years the level of extraction of gold from most ores of the Witwatersrand has been consistently above 95 per cent, so that any possible improvements in recovery must be marginal and limited to the few per cent now left in the residues from the various types of metallurgical circuits. These amount to only some 0.2 to 0.8 grams per tonne of ore, but recent research investigations by the South African mining industry and by the National Institute for Metallurgy have begun to show some worth-while means of increasing overall recovery.

These developments were reviewed in a paper presented to the annual meeting of the Metallurgical Society of the A.I.M.E. in New York by Dr. P. A. Laxen, Chief Scientist to the National Institute for Metallurgy.

The gold reefs in the Witwatersrand contain also uranium and pyrite, and some of the improvements to the standard gold extraction process have been associated with the recovery or concentration of one or both of these. A "reverse-leach" process, for example, in which acid treatment for the extraction of uranium precedes cyanidation, has been found to increase gold recovery by exposing the gold in acid-soluble minerals such as uraninite and in partly soluble silicates. Flotation prior to reverse leaching is used most successfully at one mine as a preconcentration procedure. Approximately 80 per cent of the gold, 25 per cent of the uranium and over 80 per cent of the sulphur report in the flotation concentrate, which is about 3 per cent of the weight of the ore. Gravity concentration, which is still widely used, is also the focal point of renewed interest on a number of mines, the trend being towards bulk rougher concentrates for maximum recovery.

Considerable attention is also being given to the application of concentration procedures to both current and past residues. Flotation of some current residues, for example in which thucolite is an important carrier of residual gold, appears justifiable. Some of the host minerals for uranium and gold are feebly magnetic, and wet high-intensity magnetic separation has also given promising results in both laboratory and pilot plant scale for uranium and gold recovery.

Flotation is reported as the method being considered by the Anglo-American Corporation for retreatment of one million tons of residues a month on the East Rand. The pyrite, which will be used for manufacture of sulphuric acid, and the recovered gold, are the justification for the undertaking.

Improvements in cyanidation have resulted from a closer study of operating variables such as the $\mathrm{pH}$ values and temperatures of the pulps, with continuous monitoring of the cyanide concentration, and this has again led to greater recovery.

Research in the Chamber of Mines laboratories is being carried out on the use of solvent extraction and ion exchange for the recovery of gold from solution. 